\title{
A CONSTRUÇÃO DO CONHECIMENTO GEOGRÁFICO UTILIZANDO A LITERATURA COMO RECURSO PEDAGÓGICO: UM ESTUDO DE CASO EMPREGANDO A LITERATURA DE JÚLIO VERNE
}

\author{
The construction of geographical knowledge using literature as a pedagogical resource: a case \\ study employing Julio Verne's Literature \\ Alexandre Dalla Barba de Almeida* \\ *Mestrando do PPG em Geografia -UFRGS - alexandredallabarba@gmail.com.
}

Recebido em 15/08/2018. Aceito para publicação em 25/08/2018.
Versão online publicada em 03/08/2018 (http://seer.ufrgs.br/paraonde)

\begin{abstract}
Resumo:
Este artigo objetiva expor os resultados provisórios de nossa pesquisa, em andamento, que almeja verificar as possibilidades de construção do conhecimento geográfico considerando a Literatura enquanto linguagem. Para alcançar este objetivo, nosso processo investigatório apresenta um movimento metodológico que busca a articulação entre a Pesquisa Qualitativa e o Paradigma da Complexidade. No momento, os resultados da pesquisa apontam para os potenciais da Literatura como um instrumento que, se abordada sob a luneta da Geografia, pode auxiliar no processo dialógico de ensinar e aprender de nossa ciência. Também apontam a heterogeneidade de abordagens atribuída a Literatura pelo conhecimento geográfico e sua utilização como uma ferramenta que pode auxiliar na (re)construção do conceito geográfico de Paisagem.
\end{abstract}

Palavras-chave: Geografia; Ensino; Literatura.

\begin{abstract}
:
This article aims to expose the provisional results of our ongoing research that seeks to verify the possibilities of constructing geographic knowledge considering Literature as a pedagogical language. To achieve this goal, our research process presents a methodological movement that seeks to articulate qualitative research and the Paradigm of Complexity through the execution of a case study involving the book Around the World in Eighty Days written by Jules Verne (2013). At the moment, the results of the research point to Literature as an instrument that, if approached under the scope of Geography can help in the dialogical process of teaching and learning of our science. They also point out the heterogeneity of approaches attributed to Literature by geographic knowledge and its use as a tool that can help in the (re)construction of the concept of Landscape.
\end{abstract}

Key-words: Geography; Teaching; Literature.

\section{Introdução}

É possível apontar um ensino de Geografia "ideal”? Essa indagação parece ser delicada, sinuosa, desafiadora. Ao teorizarmos sobre o ensino quase sempre nos vemos diante dessa questão. Acreditamos que a maioria dos Sujeitos envolvidos com a educação tenha as suas próprias concepções sobre o que possa ser uma educação "ideal". Quanto aos Sujeitos envolvidos com o ensino de Geografia essa premissa não parece ser diferente.

Em verdade, pensamos que existam caminhos que possam nos levar para um "ensino melhor" de Geografia, o que se distancia do "melhor dos ensinos" que é o que estaria contido no termo "ideal". Como aponta Kaercher (2014, p. 31), com relação às teorizações sobre o ensino de Geografia: 
Há uma tendência muito grande de prescrever caminhos que, se seguidos, garantiriam a remoção dos males detectados no presente, e levaria à educação, bem como seus docentes e discentes, a uma realidade mais harmoniosa, criativa, enfim, feliz. A esse "descompasso" entre o presente (que é visto e analisado) e os nossos necessários e legítimos desejos de um futuro diferente colocamos uma forte carga ideológica de "pensamentos desejantes" (wishful thinking)".

Enquanto Sujeitos com razão, emoção e sonhos aflorados também estamos correndo esse risco! Observamos que não há mal algum em pensarmos em um ensino ideal, porém, desejamos nos distanciar da senda de possíveis verdades que engessem as nossas discussões com apontamentos e "receitas" prontas. Por isso, para discutirmos o ensino de Geografia, primeiramente acreditamos ser necessário caracterizá-lo no tempo e no espaço em que estamos inseridos. Estamos na pósmodernidade em um período de aceleração dos processos de globalização, conforme aponta Castrogiovanni $(2003 ; 2007)$. Esse período caracteriza-se pela:

Globalização das ideias, padrões, valores sociomundiais e imaginários. Deve também ser visto como uma cultura de massa, que massifica, homogeiniza; como um mercado de bens culturais, universo de signos e símbolos, linguagens e significados que povoam o modo pelo qual uns e outros situam-se no mundo ou pensam, imaginam, sentem e agem. (CASTROGIOVANNI, 2003, p. 83).

Dessa forma, técnica, ciência e conhecimento se articulam para dar ao mundo uma dinamicidade e uma complexidade de significativa magnitude. Essa dinamização ecoa sobre o processo de aprender, que parece não acompanhar satisfatoriamente tais modificações.

Como buscarmos, então, uma aprendizagem significativa de Geografia que leve em conta este tempo e este espaço onde Sujeitos professores e Sujeitos alunos vivem? Para caminharmos nessa direção acreditamos que são demandadas práticas pedagógicas que valorizem a curiosidade e que promovam a construção de conhecimento geográfico a partir de diferentes caminhos, levando em conta as particularidades deste período. Um desses caminhos, para nós, parece ser a incorporação de diferentes linguagens ao processo de ensino-aprendizagem. Dentre essas linguagens está a Literatura, uma linguagem que, enquanto recurso pedagógico pode auxiliar nos processos de construção de conhecimento geográfico. Por isso, nossa pesquisa tem a Literatura como um de seus principais enfoques.

Nosso principal objetivo nessa pesquisa, em andamento, é verificar as possibilidades de construção do conhecimento geográfico a partir da Literatura. Para cumprir tal objetivo, norteamo-nos por meio dos seguintes objetivos específicos: investigar se é possível, ou não, transformar o texto literário em texto geográfico utilizando a literatura de Júlio Verne ${ }^{1}$; elaborar, se possível, propostas didáticas utilizando a literatura de Júlio Verne enquanto recurso pedagógico para a (re)construção do conceito de Paisagem no processo de ensino-aprendizagem; aplicar, se assim for, na Educação Básica, propostas pedagógicas que possibilitem a construção, ou não, do conhecimento geográfico por meio da Literatura de Júlio Verne. A partir desses objetivos que movimentam nosso processo investigatório ensejamos responder á seguinte questão de pesquisa: é possível, ou não, construir conhecimento geográfico por meio da Literatura?

Neste artigo pretendemos apresentar os caminhos que estamos trilhando em nossa pesquisa apontando e discutindo aspectos práticos, teóricos e metodológicos que nos guiam nesta senda de (re)construção de conhecimento.

\footnotetext{
1 Nascido na França em 1828 e falecido em 1905, o autor elaborou cerca de oitenta obras, uma extensa bibliografia que constitui a coleção Voyages Extraordinaries - Viagens Extraordinárias -, um conjunto de obras literárias que mesclam ciência (com atenção privilegiada à Geografia), aventura e ficção e que se desenvolvem nas mais heterogêneas localidades do globo terrestre.
} 


\section{A Literatura na construção do conhecimento geográfico: ciência e ensino}

A Literatura há muito tempo é objeto de curiosidade e reflexão pela Ciência Geográfica, conforme apontam Marandola e Oliveira (2009). Quando se trata de buscarmos aproximações entre a Geografia e a Literatura parece desafiante e até mesmo duvidoso relacioná-las em um primeiro momento: uma é ciência, outra é arte. Ambas parecem distantes em seus universos. Porém, quando se adentra em uma análise mais aprofundada dessas áreas do conhecimento as barreiras diminuem, as fronteiras estreitam-se, as similaridades aparecem e possíveis conexões parecem surgir.

A Geografia e a Literatura nasceram juntas na Grécia Antiga em um contexto onde não era possível reconhecer claramente as barreiras entre uma ou outra, conforme apontam Marandola e Oliveira (2009). Com o passar do tempo e o advento da modernidade - mais especificamente com o surgimento da sociedade urbano-industrial que impetrou o esfacelamento dos saberes em prol das especializações demandadas por esse período e que perduram até o presente - esta tratou de separálas claramente: a Geografia enveredou-se para a ciência enquanto a Literatura foi associada às artes (GOETTERT e MARSCHNER, 2011). Essa disjunção arbitrária impôs resistência por parte dos geógrafos em considerar as obras literárias como fontes de possíveis descobertas.

O geógrafo Milton Santos (1994, p. 07), certa vez quando questionado sobre o que a Geografia havia deixado de lado para ocasionar a perda do status de disciplina prioritária na organização da sociedade, respondeu:

A poesia e a filosofia, acopladas à geografia antiga. Nos tempos de Heródoto, os viajantes faziam geografia sem o intuito de fazê-la. A meu ver, o maior erro que a geografia cometeu foi o de querer ser ciência, em vez de ciência e arte. Ela abandonou a literatura, mudou sua forma de escrever e sucumbiu ao método científico.

Mesmo se distanciando das artes e se afirmando como ciência autônoma ao longo do século XIX, logo os geógrafos começaram a considerar a Literatura como um possível caminho de investigação para a Ciência Geográfica. Mesmo esparsos e com pouca aceitação no ambiente acadêmico, brotaram em diferentes escolas do pensamento geográfico teorizações sobre a Literatura. A partir da década de 1970, a abordagem geográfica sobre a Literatura tomou maior impulso estimulada pelo surgimento das correntes humanistas e culturais que deram novas perspectivas para essa relação.

Mas e no ensino? Será que a Geografia pode, ou não, se utilizar da Literatura para auxiliar na (re)construção do conhecimento geográfico? A incorporação de múltiplas linguagens e a busca por elementos que sirvam para aprimorar o ensino permitindo diferentes possibilidades de leitura sobre o Espaço Geográfico parece não ser algo recente. Tampouco no que tange à utilização da Literatura com um desses elementos. Sua utilização como recurso pedagógico não é algo novo no ensinar Geografia.

Todavia, parece que as discussões acerca da Literatura no ensino de Geografia ficaram secundarizadas, sendo retomadas com maior ênfase nas últimas décadas. Marandola (2006) aponta um aumento significativo de trabalhos que dizem respeito à Literatura na educação geográfica, incentivados por novas linhas de estudo que visam estudar a relação entre a Geografia e a Literatura. Pensamos que a Literatura possa auxiliar o ensino de nossa ciência como um recurso que pode dar maior sentido ao processo de ensinar e aprender, conferindo vida e poesia ao conhecimento geográfico. Isto posto, a seguir apontaremos nosso horizonte metodológico de pesquisa. 


\section{Metodologia}

A Pesquisa Qualitativa em interface com o Paradigma da Complexidade apresenta-se, para nós, como um modo de investigação que pode dar conta das multidimensionalidades inerentes ao nosso processo investigatório nos direcionando em busca de verdades provisórias em meio ao contexto educacional ao qual nossa ciência também é integrante e que desejamos imergir. Conforme Castrogiovanni (2004), a Pesquisa Qualitativa possibilita a busca por verdades temporárias por um caminho que propicia maior flexibilidade metodológica. Este caminho possui um caráter complexo, ou seja, parece ser um tipo de pesquisa que vai ao encontro da Complexidade.

Nesta imbricação entre o Paradigma da Complexidade e a Pesquisa Qualitativa ancoraremos os nossos objetivos de pesquisa. Por isso, acreditamos ser pertinente realizar a retomada de nossos objetivos específicos por meio dos quadros a seguir, apontando detalhadamente quais serão as possíveis ações realizadas para atingir cada um dos mesmos. Rememorando que nosso objetivo geral consiste em verificar as possibilidades de construção do conhecimento geográfico a partir da Literatura, considerando-a enquanto linguagem.

Nosso objetivo específico A consiste em:

A. Investigar se é possível, ou não, transformar o texto literário em texto geográfico. utilizando a literatura de Júlio Verne.

\begin{tabular}{|c|c|}
\hline Onde? & $\begin{array}{l}\text { Pesquisa documental em fontes que envolvem técnicas científico- } \\
\text { metodológicas e uma obra literária da bibliografia do literato Júlio Verne. }\end{array}$ \\
\hline Como? & $\begin{array}{l}\text { Pretendemos utilizar a técnica de análise de conteúdo sugerida por } \\
\text { Bardin (2004). A partir dessa técnica desejamos verificar como podemos, } \\
\text { ou não, "geografizar" a obra literária A volta ao mundo em oitenta dias de } \\
\text { Júlio Verne (2013)2, isto é, como podemos explorá-la sob o ponto de vista } \\
\text { do ensinar Geografia, verificando de quais formas podemos problematizar } \\
\text { o seu conteúdo. }\end{array}$ \\
\hline Quando? & $2017 / 1$ \\
\hline Por quê? & $\begin{array}{l}\text { Faremos essa investigação para analisar a obra de Júlio Verne (2013) } \\
\text { como um possível recurso pedagógico que pode auxiliar ou não na } \\
\text { (re)construção do conhecimento geográfico. Pensamos que, com a técnica } \\
\text { da análise de conteúdo será possível verificar se essa obra literária, } \\
\text { publicada há mais de } 140 \text { anos, pode ser trabalhada no ensinar Geografia e } \\
\text { quais são os temas geográficos que podem ser abordados a partir da } \\
\text { mesma. Como apontamos anteriormente, acreditamos que o conceito de } \\
\text { Paisagem seja o principal conceito que a Literatura pode nos ajudar em sua } \\
\text { (re)construção. Por isso, a partir dele, pensamos que será possível abordar } \\
\text { temas geográficos que o envolvam e que serão examinados na obra por } \\
\text { intermédio da análise de conteúdo. }\end{array}$ \\
\hline
\end{tabular}

Quadro 1 - Passos a serem efetuados para alcançar o objetivo específico A. Elaborado pelo autor.

Como objetivo específico B, temos o seguinte:

\footnotetext{
${ }^{2}$ Nesta obra, somos apresentados às personagens Phileas Fogg e seu escudeiro Chavemestra. Após realizar uma aposta com companheiros do clube ao qual frequenta, Phileas Fogg decide empenhar-se em realizar a volta ao mundo em, no máximo, 80 dias. Ao longo da aventura, somos apresentados a descrições detalhadas dos diversos locais do mundo por onde Fogg e Chavemesta percorrem, além de temas que envolvem coordenadas geográficas, fusos horários, meios de transporte etc. Optamos pela escolha desta obra, pois pensamos que ela seja uma das obras mais difundidas e traduzidas da extensa bibliografia de livros escritos por Júlio Verne, tendo se tornado base para filmes cinematográficos, peças de teatro e documentários.
} 
B. Elaborar, se possível, propostas didáticas utilizando a Literatura de Júlio Verne enquanto recurso pedagógico para a (re)construção do conceito de Paisagem no processo de ensinoaprendizagem.

\begin{tabular}{|c|l|}
\hline Onde? & Pesquisa documental. \\
\hline Como? & $\begin{array}{l}\text { A partir dos resultados da análise de conteúdo da obra de Júlio Verne } \\
\text { vamos ao encontro de nosso segundo objetivo específico, ao qual visamos } \\
\text { elaborar atividades pedagógicas que envolvam o uso do livro A volta ao } \\
\text { mundo em 80 dias na Educação Básica. Embasaremos as nossas criações a } \\
\text { partir de autores que discorrem sobre aspectos teórico-epistemológicos e } \\
\text { práticos que envolvem a educação e o ensinar Geografia como } \\
\text { Castrogiovanni et al. (2016, 2015, 2014a, 2014b, 2013, 2011, 2000), } \\
\text { Cavalcanti }(2015,2010), \text { Costella e Schaffer (2012), Freire (1987, 2011), } \\
\text { Kaercher (2014) e Morin (2015, 2011, 2010). }\end{array}$ \\
\hline Quem & Teóricos que discorrem sobre o ensinar Geografia. \\
\hline Qunvolve? & Indefinido. \\
\hline Quando? & $2017 / 1$ \\
\hline Por quê? & Visamos elaborar as atividades para, em um segundo momento, \\
\hline
\end{tabular}

Quadro 2 - Passos a serem efetuados para alcançar o objetivo específico B. Elaborado pelo autor.

Por fim, enquanto objetivo específico C, possuímos o seguinte:

C. Aplicar, se assim for, na Educação Básica, propostas pedagógicas que possibilitem a construção, ou não, de conhecimentos geográficos por meio da Literatura de Júlio Verne.

\begin{tabular}{|c|c|}
\hline Onde? & $\begin{array}{l}\text { Em uma turma de sexto da Educação Básica de uma escola da rede } \\
\text { pública de Ensino Fundamental situada no município de Porto Alegre. }\end{array}$ \\
\hline Como? & $\begin{array}{l}\text { A partir de um estudo de caso onde aplicaremos as atividades } \\
\text { desenvolvidas. Além de realizarmos a verificação, por meio de análise de } \\
\text { conteúdo, das atividades desenvolvidas pelos alunos, efetuaremos } \\
\text { entrevistas semiestruturadas. Estas entrevistas ocorrerão após a execução } \\
\text { das atividades para investigarmos quais foram os comportamentos e quais } \\
\text { são as avaliações dos educandos frente às atividades construídas } \\
\text { envolvendo a Literatura de Júlio Verne. Aplicaremos os princípios } \\
\text { Dialógico, de Recursão Organizacional e Hologramático que compõem o } \\
\text { Paradigma da Complexidade (MORIN, 2003) para analisarmos os dados } \\
\text { coletados. }\end{array}$ \\
\hline Quem & Alunos de sexto ano da Educação Básica. \\
\hline Quantas? & \multicolumn{1}{|c|}{ Indefinido. } \\
\hline Quando? & 2017/2 \\
\hline Por quê? & Para inferir se as atividades desenvolvidas podem auxiliar, ou não, na \\
\hline
\end{tabular}

Quadro 3 - Passos a serem efetuados para alcançar o objetivo específico C. Elaborado pelo autor.

A escolha específica pelo sexto ano do Ensino Fundamental da Educação Básica para a aplicação do estudo de caso se dá por conta de que os livros didáticos aprovados pelo Programa Nacional do Livro Didático de 2017 - PNLD 2017 - têm o sexto ano como série em que o objeto de estudo da Geografia (o Espaço Geográfico) e o conceito de Paisagem são programaticamente abordados. Chegamos a estes apontamentos a partir da análise de três livros didáticos aprovados no PNLD 2017: Furquim Jr. (2015), Ribeiro (2015) e Sampaio (2015). 


\section{Resultados provisórios e discussão}

0 presente movimento investigatório ainda encontra-se em andamento. No entanto parece ser possível apontar alguns resultados provisórios encontrados ao longo de nossas pesquisas documentais. Em um primeiro momento pesquisamos pontos que pudessem aproximar a Geografia e a Literatura. Ambas, à sua maneira e a partir de instrumentais próprios, ao nos permitirem pensar sobre os Sujeitos, parecem convergir para um ponto: a reflexão sobre a condição humana, que para Morin $(2011,2015)$ deveria ser o elemento essencial de todos os ensinos objetivando que "cada um, onde quer que se encontre, tome conhecimento e consciência, ao mesmo tempo, de sua identidade complexa e de sua identidade comum a todos os outros humanos" (MORIN, 2011, p. 16).

Além da condição humana, um dos aspectos que caracterizam a Literatura diz respeito à narração e à descrição, características textuais presentes nas obras literárias. Gomes (2013) traça uma relação entre essas características da Literatura com a Geografia. $\mathrm{O}$ autor inicialmente apresenta essas duas características, apontando que a descrição corresponde à apresentação de características, a reunião de elementos, tipificações, individualizações e apresentações.

Já a narração, para o referido autor, corresponde a um componente cronológico essencial, a uma sucessão de elementos em uma escala temporal que é constituída, dessa forma, pelo estabelecimento de uma linha de coerência entre atos, eventos ou elementos que ocorrem temporalmente. Dessa forma, GOMES (2013) relaciona-os a conceitos da Geografia e chega ao seguinte apontamento:

Na geografia, a narração corresponderia à ideia de processos. [...] Em oposição, a descrição teria maior compromisso com a simultaneidade de elementos, com a composição e até a simbologia, ou seja, com a relação da forma com os conteúdos. Os procedimentos descritivos são um traço muito forte na tradição geográfica (GOMES, 2013, p. 68-69).

A partir das narrações e das descrições presentes na Literatura, acreditamos poder encontrar elementos para a construção de conceitos que balizam a nossa ciência como forma de explorá-la — ou não - como um possível recurso para a construção do conhecimento geográfico na Educação Básica. Acreditamos que talvez seja possível adentrar na Literatura abordando-a por meio do conceito de Paisagem e de nosso objeto de estudo principal: o Espaço Geográfico.

O geógrafo Paul Claval (1999) norteia-nos em relação ao conceito de Paisagem concebendo-a como uma representação cultural. Nessa perspectiva, a Paisagem é a realização e a materialização de ideias dentro de diferentes sistemas de significação. A Paisagem ao qual nos referimos constitui uma paisagem literária imaginada, imagens de um espaço mentalmente concebido que pode ser apresentado aos alunos por meio da leitura de obras literárias. 0 trabalho a partir da leitura da descrição dessas paisagens pode ser — ou não — um caminho para abordagem.

O objeto principal de estudo de nossa ciência - o Espaço Geográfico - também parece ser, neste momento, uma possibilidade de abordagem. Milton Santos (1997, p. 51) caracteriza o Espaço Geográfico como sendo o "conjunto indissociável, solidário e também contraditório, de sistemas de objetos e sistemas de ações, não considerados isoladamente, mas como um quadro único no qual a história se dá". Acreditamos que a Literatura pode permitir a reflexão sobre os Sujeitos, a sociedade e a natureza, pois as obras literárias são elaboradas em um Espaço Geográfico posto em determinado momento histórico. Isso faz com que as obras literárias sejam produtos construídos em meio a processos geográficos, históricos, políticos, econômicos, sociais e culturais que podem apresentar traços do tempo e do espaço onde foram produzidas.

Esses traços interessam aos nossos objetivos enquanto professores, pois a Geografia, enquanto disciplina da Educação Básica que visa construir conhecimento espacial, pode valorizar o seu objeto de estudo permitindo análises múltiplas. E a Literatura pode ser, em nossa visão, uma dessas ferramentas de análise. 


\section{Referências}

BARDIN, Laurence. Análise de conteúdo. 3ª Ed. Lisboa: Edições 70, 2004.

CASTROGIOVANNI, Antonio Carlos; TONINI, Ivaine Maria; KAERCHER, Nestor André; COSTELLA, Roselane Zordan. (Orgs.). Para ensinar geografia - oscilações. Porto Alegre: Editora Letra1, 2016.

; TONINI, Ivaine Maria; KAERCHER, Nestor André; COSTELLA, Roselane Zordan. (Orgs.).

Movimentos no ensinar geografia - rompendo rotações. Porto Alegre: Evangraf: 2015.

; GIORDANI, Ana Claudia; TONINI, Ivaine Maria; COSTELLA, Roselane Zordan; KAERCHER, Nestor André. (Orgs.). Aprender a ensinar geografia: a vivência como metodologia. Porto Alegre: Evangraf, 2014a.

; TONINI, Ivaine Maria; GOULART, Lígia Beatriz; KAERCHER, Nestor André; MARTINS, Rosa Elizabete Militz Wypyczynski. (Orgs.). O ensino de geografia e suas composições curriculares. Porto Alegre: Mediação, 2014b.

; TONINI, Ivaine Maria; KAERCHER, Nestor André. (Orgs.). Movimentos no ensinar geografia. Porto Alegre: Imprensa Livre: Espaço Lugar-Cultura, 2013.

; ROSSATO, Maíra Suertegaray; CÂMARA, Marcelo Argenta; LUZ, Robson Réus Silva da. Ensino da geografia: caminhos e encantos. 2ª Ed. Porto Alegre: EDIPUCRS, 2011.

Para entender a necessidade de práticas prazerosas no ensino de geografia na pósmodernidade. In: REGO, Nelson; CASTROGIOVANNI, Antonio Carlos; KAERCHER, Nestor André. (Orgs.). Geografia: práticas pedagógicas para o ensino médio. Porto Alegre: Artmed, 2007.

. E agora, como fica o ensino de geografia com a globalização?. In: CASTROGIOVANNI, Antonio Carlos; CALLAI, Helena Copetti; SCHAFFER, Neiva Otero; KAERCHER, Nestor André. Geografia em sala de aula: práticas e reflexões. Porto Alegre: Editora da UFRGS, 2003.

; CALLAI, Helena Copetti; KAERCHER, Nestor André. Ensino de geografia: práticas e textualizações no cotidiano. Porto Alegre: Mediação, 2000.

CAVALCANTI, Lana de Souza. O ensino de geografia na escola. Campinas: Papirus, 2015.

Geografia, escola e construção de conhecimentos. Campinas, SP: Papirus, 2010.

CLAVAL, Paul. A geografia cultural. Florianópolis: UFSC, 1999.

COSTELLA, Roselane Zordan; SCHAFFER, Neiva Otero. A geografia em projetos curriculares - ler o lugar e compreender o mundo. Porto Alegre: Edelbra, 2012.

FREIRE, Paulo. Pedagogia da autonomia. São Paulo: Paz e Terra, 2011.

Pedagogia do oprimido. 17a ed. Rio de Janeiro: Paz e Terra, 1987.

FURQUIM Jr., Laércio. Geografia cidadã: 6º ano, ensino fundamental. São Paulo: Editora AJS, 2015.

GOETTERT, Jones Dari.; MARSCHNER, Roberto. (orgs.). Transfazer o espaço: ensaios de como a literatura vira espaço e vice versa. Dourados, MS: Ed. UFGD, 2011.

GOMES, Paulo César da Costa. O lugar do olhar: elementos para uma geografia da visibilidade. Rio de Janeiro: Bertrand Brasil, 2013.

KAERCHER, Nestor André. Se a geografia escolar é um pastel de vento o gato come a geografia crítica. Porto Alegre, Evangraf, 2014.

MARANDOLA, Janaína de Alencar Mota e Silva. O geógrafo e o romance: aproximações com a cidade. Geografia. Rio Claro, SP: v.31, n.1, p. 61-81, jan./abr. 2006.

MARANDOLA Jr., Eduardo; OLIVEIRA, Lívia de. Geograficidade e espacialidade na literatura. Geografia. 
Rio Claro, SP: v.34, n.3, p. 487-508, set./dez. 2009.

MORIN, Edgar. A cabeça bem-feita. 22a Ed. Rio de Janeiro: Bertrand Brasil, 2015.

UNESCO, 2011.

Os sete saberes necessários à educação do futuro. 2a Ed. São Paulo: Cortez; Brasília, DF, Ciência com consciência. 13를 Ed. Rio de Janeiro: Bertrand Brasil, 2010.

Introdução ao pensamento complexo. 4⿳亠丷厂 Ed. Lisboa: Instituto Piaget, 2003.

RIBEIRO, Wagner Costa. Por dentro da Geografia: 6a ano. São Paulo: Saraiva, 2015.

SAMPAIO, Fernando dos Santos. Para viver juntos: 6 ano. São Paulo: Edições SM, 2015.

SANTOS, Milton. A natureza do espaço. São Paulo: Hucitec, 1997.

. Entrevista com Milton Santos. Revista Veja. Rio de Janeiro: Abril, ano 27, no 46, 1994, p. 07.

VERNE, Júlio. A volta ao mundo em 80 dias. Porto Alegre: L\&PM, 2013. 